\title{
Mortality Associated With Acute Respiratory Distress Syndrome 2009-2019: A Systematic Review and Meta- regression
}

\author{
Divyajot Sadana \\ Cleveland Clinic https://orcid.org/0000-0002-6121-9423 \\ Simrat Kaur \\ Cleveland Clinic Foundation: Cleveland Clinic \\ Kesavan Sankaramangalam \\ Cleveland Clinic Foundation: Cleveland Clinic \\ Kinjal Banerjee \\ Cleveland Clinic Foundation: Cleveland Clinic \\ Matthew Siuba \\ Cleveland Clinic Foundation: Cleveland Clinic \\ Valentina Amaral \\ Cleveland Clinic Foundation: Cleveland Clinic

\section{Shruti Gadre} \\ Cleveland Clinic Foundation: Cleveland Clinic
}

\section{Heather Torbic}

Cleveland Clinic Foundation: Cleveland Clinic

\section{Sudhir Krishnan}

Cleveland Clinic Foundation: Cleveland Clinic

\section{Abhijit Duggal ( $\square$ duggala2@ccf.org)}

Department of Critical Care, Respiratory Institute, Cleveland Clinic, Cleveland, Ohio, United States https://orcid.org/00000003-4220-2359

\section{Research}

Keywords: ARDS, mortality, meta-analysis, meta-regression, heterogeneity

Posted Date: November 2nd, 2020

DOI: https://doi.org/10.21203/rs.3.rs-99742/v1

License: (a) (i) This work is licensed under a Creative Commons Attribution 4.0 International License. Read Full License 


\section{Abstract}

Background: Acute respiratory distress syndrome (ARDS) is a common occurrence in an intensive care unit. The reported mortality in studies evaluating acute respiratory distress syndrome is highly variable. The adherence to ventilatory specific and adjunctive therapies is also highly variable. We investigated the mortality of ARDS since the $2009 \mathrm{H} 1 \mathrm{~N} 1$ pandemic and examined the adherence to ventilatory specific and adjunctive therapies.

Methods: We performed a systematic search in MEDLINE and EMBASE using a highly sensitive criterion from January 2009 to May 2019. We then ran a proportional meta-analysis for mortality and a meta-regression analysis using certain variables to address heterogeneity.

Results: We screened 5361 citations, of which 85 fully met inclusion criteria. The weighted pooled mortality of all 85 studies published from 2009 to 2019 was $38 \%(95 \% \mathrm{Cl} 35,40)$. Mortality was higher in observational studies [40\% $(95 \% \mathrm{Cl} 37,42)]$ compared to RCTs [35\% $(95 \% \mathrm{Cl} 30,39)],(p=0.04)$ Significant variability exists in literature of reported tidal volumes, positive end expiratory pressures, plateau pressures, and use adjunctive therapies. The tidal volumes in our systematic review ranged from 5.8 to $8.9 \mathrm{ml} / \mathrm{kg}$ with a mean of $7.2 \mathrm{ml} / \mathrm{kg}$. PEEP ranged from 4.6 to $16.1 \mathrm{~cm} \mathrm{H} 20$ at the time of enrollment with a mean of $10.2 \mathrm{~cm} \mathrm{H} 2 \mathrm{O}$. Reported plateau pressures ranged from 21.0 to $35.1 \mathrm{~cm} \mathrm{H} 2 \mathrm{O}$, with a mean of $25.6 \mathrm{~cm} \mathrm{H} 2 \mathrm{O}$. Higher reported initial PaO2/FiO2 ratios were associated with decreased mortality. A trend towards decreased mortality was seen with lower reported tidal volumes in the included studies.

Conclusions: Over the last decade, the mortality in ARDS has marginally improved and there exists significant heterogeneity in the utilization of low tidal volume strategies, application of PEEP and the adoption of adjunctive therapies in the management of these patients in published literature.

\section{Background}

Acute respiratory distress syndrome (ARDS) accounts for approximately 10 percent of intensive care unit (ICU) admissions, with a mortality rate ranging from 35-45 percent(1). Phua et al showed that the mortality among observational studies and randomized controlled trials remained static from the implementation of the 1994 AECC definition for ARDS to 2006(2). Since the publication of that meta-analysis, an influenza pandemic with a high prevalence of ARDS occurred, a new definition of ARDS was developed(3) and several landmark randomized controlled trials evaluating various interventions were published(49).

Over the last two decades lung-protective ventilation (LPV) strategies [tidal volume (Vt) 6-8 mL/kg predicted body weight and low plateau airway pressures (Pplat) $(<30 \mathrm{cmH} 20)$ ] remains the mainstay of ARDS management. Adherence to LPV strategies has consistently shown to improve patient survival(10). Use of Prone Position ventilation (PP)(9) in patients with moderatesevere ARDS is the only other therapeutic intervention that has been associated with improved survival. Use of continuous neuromuscular blocking agents $(\mathrm{NMBA})(4,11)$ has been disparate results amongst the two major trials that have evaluated this question. Other interventions including use of higher positive end expiratory pressure (PEEP) $(12,13)$, inhaled pulmonary vasodilators $(14,15)$ and diuretics $(16)$ improve oxygenation and duration of mechanical ventilation respectively, but their use has not been associated with a mortality benefit. Based on the current evidence early, consistent use of extracorporeal membrane oxygenation (ECMO) cannot be justified, and this therapy needs to be considered after failure of conventional mechanical ventilation $(5,17,18)$. But more importantly independent of the quality or strength of evidence the application of all these therapies in ARDS remains inconsistent and is predominantly influenced by physician comfort and discretion(1). As a result, significant heterogeneity is seen in the adoption and application of these evidence-based therapies in the published literature.

We conducted a systematic review and meta-analysis to investigate mortality associated with ARDS since the $2009 \mathrm{H} 1 \mathrm{~N} 1$ pandemic. We evaluated temporal changes in mortality over the study period. Due to the presence of heterogeneity in application of conventional and adjunctive management strategies in ARDS patients, we also evaluated the impact of specific 
intervention such as reported tidal volume, PEEP and use of adjunctive therapies on the reported mortality in the included studies.

\section{Methodology}

\section{Search strategy}

We electronically searched MEDLINE and EMBASE (January 2009 to May 2019) using a highly sensitive strategy to identify the relevant studies. For potentially relevant articles the full text was obtained for review; for these articles, all references were inspected to supplement our search. Details of the search strategy are reported in the supplementary files. We limited our search strategy to articles published in English.

\section{Study selection}

We included both randomized controlled trials (RCT) and observational studies for the purpose of this systematic review. Using standardized criteria, two reviewers (DS and KS) reviewed titles and abstracts identified by the search strategy independently and in duplicate, retrieving studies that either reviewer thought relevant for full-text review. Disagreements between reviewers in study selection and data extraction were resolved by the senior author (AD). We selected observational studies and RCTs enrolling at least 50 adults with acute lung injury (ALI) / acute respiratory distress syndrome (ARDS) and reporting mortality. We only included studies where $100 \%$ of the sample met any criteria for ARDS. We excluded reports available only in abstract form, duplicate reports and animal studies.

\section{Data extraction}

Two authors (DS and KS) independently extracted all the data. Extracted data included: geography (county, continent, institutions); duration of study (months, years); ARDS definition used [Berlin, American European Consensus Conference (AECC), or other]; patient characteristics [age, severity (Pa/FiO2 ratio, APACHE II, SAPS, SOFA)]; ventilator specific variables (Vt, PEEP, Pplat); adjunctive therapy [inhaled vasodilators, NMBA, High Frequency Oscillatory Ventilation (HFOV), PP, and ECMO]; and all reported mortality. Driving pressure was calculated using the reported PEEP and Pplat(19). The data from RCTs and observational studies that contained multiple arms were combined for analysis (if reported in means and standard deviation). If a study contained an arm dedicated to investigating an adjunctive therapy versus control, only the control arm from that study was included, so as to pertain to all ARDS patients. Any missing data is reported in the study table in the supplementary appendix. The primary outcome was short term mortality. Short term mortality was defined as hospital mortality where reported, as it was the most often reported. If not reported then ICU mortality, 90-day mortality, 60-day mortality, and 28/30-day mortality were substituted, in this order of preference.

\section{Risk of bias assessment}

To assess for risk of bias, two authors independently reviewed all included studies. The tool Cochrane RoB-2 was utilized to assess RCTs(20). Using this tool we evaluated five different domains for each RCT and determined an overall risk of bias. The ROBINS-1 tool was utilized for observational studies(21). Using this tool we evaluated seven different domains for each observational study and determined an overall risk of bias. The overall risk of bias for both RCTs and observational studies was determined by the highest risk allotment in any of the categories.

\section{Data analysis}

Baseline characteristics between observational studies and RCTs were compared using student's $t$ test and chi squared tests, for continuous and categorical variables respectively. We performed a proportion meta-analysis using random-effects models to obtain pooled estimates of mortality and $95 \%$ confidence intervals (Cls) for all observational studies and all RCTs separately(22). We used Cochran's Q statistic and 12 to test for heterogeneity among studies(23). To further explore heterogeneity among studies we formed logistic meta-regression models to evaluate the association between selected 
variables (PaO2/FiO2 ratios, Vt, PEEP, Pplat, driving pressure, mean age, APACHE II, SOFA, NMBA, PP, and ECMO) and mortality(24). We also ran a cumulative mortality analysis using median year of enrollment to evaluate the trend of mortality from our literature collection from 2009 to 2019(25). A p value of $£ 0.05$ was considered to be statistically significant. Funnel plot analysis and Egger's test were done to investigate for publication bias $(26,27)$. The statistical analysis was conducted using Stata Version 15.1 (StataCorp LP, College Station, TX.). Two sensitivity analysis were also conducted to address certain aspects of our study and their effects on our findings. One focusing on combining both the intervention and control arms of studies which focused on one adjunctive therapy and another including only on studies reporting hospital mortality.

\section{Results}

\section{Study Selection}

Our search strategy yielded 5361 citations after de-duplication. We reviewed full texts for 1523 articles for a detailed evaluation and included 85 articles in our qualitative assessment (Figure 1). The final selection of 85 articles included 30 RCTs (35.3\%) and 55 observational studies (64.7\%). 19,963 patients were enrolled in the included studies. Among the 85 included studies, 9 studies investigated an adjunctive therapy versus control, and thus only the control arm was included in the primary analysis. But we included both arms of the 9 studies in a sensitivity analysis which consisted of 21,328 patients. We also performed a sensitivity analysis of studies reporting hospital mortality. This analysis consisted of 15 RCTs (32.6\%) and 31 observational studies $(67.4 \%)$, totaling 12,168 patients.

\section{Study Characteristics}

46 (54.2\%) studies used the AECC criteria to diagnose ARDS, 36 studies (42.3\%) used Berlin Criteria, 2 (2.3\%) studies used either criteria, and 1 study (1.2\%) used the Chinese critical care medicine definition. The mean age was reported in 70 studies (82.4\%). The mean baseline $\mathrm{PaO}_{2} / \mathrm{FiO}_{2}$ ratio was reported in 72 studies (84.7\%), mean APACHE II score was reported in 38 studies (44.7\%), and mean SOFA score was reported in 32 studies (37.6\%). Tidal volume in $\mathrm{ml} / \mathrm{kg}$ was reported in 56 studies (65.9\%), PEEP was reported in 60 studies (70.6\%), Pplat was reported in 49 studies (57.7\%), and we were able to calculate the driving pressure in 44 studies (51.8\%). The use of inhaled vasodilators, NMB, HFOV, PP, and ECMO was reported in 23 (27\%), 22 (25.8\%), 9 (10.7\%), 25 (29.4\%), 20 (23.5\%) studies, respectively (Table 1). There were no differences in the baseline characteristics, severity of initial illness and use of ventilatory strategies between the RCT's and observational studies (Table 1). The lack of asymmetry on the Funnel plot and the result of the Egger's test imply that publication bias did not alter the results (e-Figures 5-6).

\section{Quality assessment}

The risk of bias for RCTs was low in twelve studies, moderate in fourteen RCTs, and high in four RCTs (e-Table 2). The high risk of bias was driven mainly by deviation from intended intervention. For observational studies the risk of bias low in two studies, moderate in forty-one studies, and high in twelve studies (e-Table 3). The high and moderate risk of bias was driven mainly by confounding given the nature of study design.

\section{Mortality}

Hospital mortality (46 studies) was most commonly reported in the included studies. In the remaining 39 studies it was substituted with ICU mortality (8 studies), 90-day mortality (3 studies), 60-day mortality (9 studies), and 28/30-day mortality (19 studies). The weighted pooled mortality of all 85 studies published from 2009 to 2019 was 38\% (95\% Cl 35,40). Mortality was higher in observational studies [40\% (95\% Cl 37, 42)] compared to RCTs [35\% (95\% Cl 30,39)], ( $p=0.04)$ (Figure 2 and Table 1). There was significant heterogeneity among the included studies $(R=92.23 \%, p<0.01)$. This heterogeneity persisted across both observational studies $(R=90.21 \%, p<0.01)$ and RCTs $(R=93.87 \%, p<0.01)$ (Figure 2$)$. Figure 2 depicts the reported mortality from the included studies listed in chronological order according to publication year. The continent where the study was performed failed to show a statistically significant different in mortality as determined by an one-way ANOVA $[F(5,79)=1.5$, $p=0.20]$. 
The reported mortality did not change based on the sensitivity analysis. The first sensitivity analysis which included both the interventional and control arm of the 9 studies evaluating a particular adjunctive therapy resulted in a pooled mortality of $37 \%$ $(95 \% \mathrm{Cl} 33,40)$ (e-Figure 7). The weighted pooled mortality was similarly higher in observational studies $[40 \%(95 \% \mathrm{Cl}, 37,43)]$ compared to RCTs [33\% (95\% Cl 29,37)] ( $p<0.01)$. The second sensitivity analysis which only included studies reporting hospital mortality (46 studies) resulted in a pooled mortality of $39 \%(95 \% \mathrm{Cl} 36,42)$ (e-Figure 8$)$. Mortality again remained higher in observational studies [41\% (95\% Cl 37,44)] compared to RCTs [34\% $(95 \% \mathrm{Cl} 28,39)](p=0.05)$. The cumulative mortality analysis, which we conducted using the median year of enrollment, displays the evolution of mortality in studies published from 2009 to 2019, excluding one study which did not mention enrollment dates(28) (Figure 3). The median year of enrollment ranges from 2000 to 2018 and on visual inspection the mortality suggests an initial decrease after which it stabilizes around the mean with little change.

\section{Meta-regression}

In our meta-regression analysis, the initial $\mathrm{PaO}_{2} / \mathrm{FiO}_{2}$ ratio in the included studies was strongly associated with the reported mortality [b coef. -0.0041 ( $95 \% \mathrm{Cl}-.0023,-.0005) ; p<0.01$ ] (Figure 4). We found significant variability in the reported ventilatory strategies and utilization of adjunctive therapies. The tidal volumes in our systematic review ranged from 5.8 to $8.9 \mathrm{ml} / \mathrm{kg}$ with a mean of $7.2 \mathrm{ml} / \mathrm{kg}$. Though not statistically significant, a very clear trend towards a mortality benefit was observed in studies with lower reported tidal volumes [b coef. 0.0337 (95\% Cl-.0009, .0680); $p=0.06$ ], see Figure 5. PEEP ranged from 4.6 to $16.1 \mathrm{~cm}$ $\mathrm{H} 2 \mathrm{O}$ at the time of enrollment with a mean of $10.2 \mathrm{~cm} \mathrm{H} 2 \mathrm{O}$. Reported plateau pressures ranged from 21.0 to $35.1 \mathrm{~cm} \mathrm{H} 2 \mathrm{O}$, with a mean of $25.6 \mathrm{~cm} \mathrm{H} 20$. Driving pressure ranged from 12.4 to 22.8 with a mean of 15.4 . Neither PEEP [b coef. $-0.0048(95 \% \mathrm{Cl}$ $-.0200, .0103) ; p=0.53$ ], Pplat [b coef. 0.0046 (95\% Cl-.0077, .0169); $p=0.45]$, nor driving pressure [b coef. $0.01382(95 \% \mathrm{Cl}$ $-.0030, .0307) ; p=0.11]$ appeared to impact mortality (e-Figures 9-11). Mean age, APACHE II, and SOFA also did not have any impact on mortality in our meta-regression (e-Figures 12-14). Reported adjunctive therapies were significantly variable in the included studies and did not have any impact on the mortality reported in our meta-regression (e-Figures 15-18). In the sensitivity analysis, which only included studies that reported hospital mortality, repeating meta-regression analysis for the same variables mentioned above produced identical results (e-Table 4).

\section{Discussion}

Our meta-analysis demonstrates a minor reduction in ARDS associated mortality since 2009. Compared to results reported by Phua et al, the cumulative reported mortality has dropped $6.9 \%$ from $44.3 \%$ to $38 \%(2)$ over the last decade. Similar to other studies, the mortality is consistently higher in observational studies compared to RCTs. The well described impact of initial severity of hypoxemia is seen in our meta-analysis and is strongly associated with mortality among the included studies.

Our study also shows that there remains significant heterogeneity and inconsistency in the reporting of key therapeutic interventions, markers of severity of illness and ventilatory strategies for patients with ARDS. This inconsistency in reporting makes the comparison of outcomes amongst these studies very difficult. Despite the development of the Berlin Definition(3) and a call for consistent reporting, this remains a problem among the studies that we evaluated. As seen in the LUNG SAFE study, ARDS still remains an underdiagnosed disease process and $40 \%$ of patients meeting ARDS criteria are never diagnosed(1). These findings suggest that diagnosis of ARDS is often delayed, with a high likelihood of delay in treatment for this diagnosis. This is especially concerning given that many of the ARDS treatments with proven benefit have only demonstrated a benefit in early $\operatorname{ARDS}(4,9,29)$.

The significant variability in use of evidence-based interventions in studies evaluating patients with ARDS is of concern. The use of ventilator specific variables, such as low tidal volume and PEEP, and adjunctive therapies, such as inhaled vasodilators, NMBAs, HFOV, PP, and ECMO, exhibit great inconsistency amongst the studies. This non-adherence to therapies with proven benefit $(4,9,30)$ among the included studies might be a significant driver to the differences in outcomes reported by different studies independent of the severity of included patients. Similar to findings in LUNG SAFE few studies mentioned the plateau pressures for the patients included in their studies and the use of adjunctive therapies is inconsistent and highly variable outside of studies evaluating a specific intervention. LUNG SAFE study revealed that less than two-thirds of patients received 
low tidal volume ventilation, $82.6 \%$ of patients received a PEEP $<12 \mathrm{~cm} \mathrm{H} \mathrm{H}, 37.8 \%$ of patients with severe ARDS received NMBAs, and only $16.3 \%$ of patients with severe ARDS were proned(1). The absence of standardization in the implementation of these therapies makes it difficult to discern their impact on outcomes. The low implementation of these therapies is surprising given a mean $\mathrm{PaO}_{2} / \mathrm{FiO}_{2}$ ratio of $132.5 \mathrm{~mm} \mathrm{Hg}$ at baseline. The overall lack of standardization and implementation of best practices observed in our study highlights the need for protocol driven ARDS management that allow the clinicians to select the most appropriate adjunctive therapies for their patient. Personalization of care to patients with ARDS may be indicated in the future as suggested by colleagues Constantin et al(31), but not before therapies with proven benefit have been systematically standardized and adopted universally. Implementation of standardized ARDS management may help to further decrease ARDS associated mortality.

Over the last decade the overall mortality reported among RCTs has remained static since the last meta-analysis(2), and remains much higher than the suggested benchmark for ARDS trials(32). Significant mortality benefit has only been seen with isolated interventions such as PP in PROSEVA(9). The reported mortality among large epidemiologic studies in ARDS over the last two decades has not changed much. The lower reported mortality in RCTs compared to observational studies is not surprising as RCTs usually ensure strict adherence to protocols, with the probable exclusion of patients with a poor prognosis(33,34). Cumulative mortality for all ARDS studies shows a less than $7 \%$ change in reported mortality across time. With the application of evidence based ventilatory and non-ventilatory therapeutic interventions we had expected to see a much larger impact on mortality in the current meta-analysis. But a lack of reporting key variables and a wide variability in the reported numbers for these variables, brings to light a significant problem that the application of these therapies are not as widely consistent as we would hope when we are caring for ARDS patients. In many cases the intervention being studied, or cointerventions of interest are tightly accounted for in individual studies, but the complex care of these patients is not nearly enough a protocolized consistent approach that we would hope for.

Our systematic review and meta-analysis has several strengths. We conducted a comprehensive literature search using broad search terms. We included studies from institutions across five continents, and report an international evaluation of the trend in ARDS mortality, as opposed to the recent findings by Zhang et al(35). The inclusion criteria were carefully predefined and carried out in a methodological fashion. Additionally, we only included studies which exclusively evaluated ARDS patients. This is the first meta-analysis evaluating ARDS mortality trends to include a meta-regression analysis evaluating ARDS treatment modalities and their association with ARDS mortality.

Despite the strengths of our meta-analysis, there are potential limitations. First, we used hospital mortality as the primary mortality in our analysis as it was most frequently reported (46 of 85 studies). With a reported incidence of mortality of 3-15\% in ARDS after discharge from the ICU(36,37), utilization of hospital mortality as our primary mortality type may have impacted our overall reported ARDS-related mortality. When hospital mortality was not available it was substituted with ICU, 90 day, 60 day, and 28/30 day mortality, in that order of preference. However, to tackle this potential inadequacy, we conducted a sensitivity analysis only including those studies reporting hospital mortality which produced identical results. Another limitation is the reporting of ventilator specific variables only at the time of patient enrollment in the majority of included studies. Although this may not represent the overall ventilator management strategy received by patients, it provides an insight into the initial management strategy, which is associated with the greatest mortality benefit. Not all studies may have reported the use of adjunctive therapies, possibly accounting for the low numbers we discovered. Finally, we included all diagnoses criteria for ARDS in our systematic review and meta-analysis and we did not stratify results based on ARDS severity. This unlikely impacted overall mortality results, however, as there was no difference in the $\mathrm{PaO}_{2} / \mathrm{FiO}_{2}$ ratio or severity scores at baseline for included studies.

\section{Conclusions}

Our systematic review and meta-analysis observed a minimal decline in ARDS related mortality over the last decade. We also saw that there remains a significant heterogeneity in reporting of both ventilator strategies and adjunctive therapies amongst the published literature. Despite established guidelines there is variability in the overall management of ARDS. Increased

Page 6/16 
clinician education regarding the importance of early recognition and implementation of best practices may help to reduce ARDS related mortality(38). Future studies should evaluate standardized ARDS treatment protocols, which implement evidencebased best practices, and their impact on mortality.

\section{Abbreviations}

ARDS - acute respiratory distress syndrome

ICU - intensive care unit

LPV - lung-protective ventilation

$\mathrm{Vt}$ - tidal volume

Pplat - plateau pressure

PP - prone position

NMBA - neuromuscular blocking agents

PEEP - positive end expiratory pressure

ECMO - extracorporeal membrane oxygenation

RCT - randomized controlled trials

$\mathrm{ALI}$ - acute lung injury

HFOV - high frequency oscillatory ventilation

APACHE II - Acute; Physiology and Chronic Health Evaluation

SOFA - Sequential Organ Failure Assessment

\section{Declarations}

Guarantor: $A D$ is the guarantor for this original research manuscript and takes full responsibility for the data and analysis.

\section{Author Contribution:}

Study concept and study design - DS/KS/AD

Data acquisition - DS/SK/KS/VA/HT

Data interpretation - DS/SK/KS/KB/MS/VA/HT/SG/SK2/AD

Statistical analysis - DS/KS/KB/AD

Drafting/critical revision of manuscript - DS/SK/KS/KB/MS/VA/SG/HT/SK2/AD

Author disclosures: All authors report no competing interests relevant to this article.

Financial disclosures: The authors have no financial support to report for this manuscript.

Funding/Support: None 
Data availability: The data used is readily available using search strategy provided.

Ethical approval and consent to participate: Was not necessary given this was a systematic review and meta-analysis of previously conducted studies

Consent for publication: No individual data presented.

Conflicts of interest: All authors have no conflicts declare

Funding: All authors have no funding to report.

Registration: PROSPERO CRD 42020149712, registered on April $28^{\text {th }} 2020$ (submitted September 2019)

\section{References}

1. Bellani G, Laffey JG, Pham T, Fan E, Brochard L, Esteban A, et al. Epidemiology, Patterns of Care, and Mortality for Patients With Acute Respiratory Distress Syndrome in Intensive Care Units in 50 Countries. JAMA [Internet]. 2016 Feb 23 [cited 2018 Dec 17];315(8):788. Available from: http://www.ncbi.nlm.nih.gov/pubmed/26903337

2. Phua J, Badia JR, Adhikari NKJ, Friedrich JO, Fowler RA, Singh JM, et al. Has Mortality from Acute Respiratory Distress Syndrome Decreased over Time? Am J Respir Crit Care Med [Internet]. 2009 Feb 20 [cited 2018 Dec 17];179(3):220-7. Available from: http://www.atsjournals.org/doi/abs/10.1164/rccm.200805-7220C

3. Acute Respiratory Distress Syndrome. JAMA [Internet]. 2012 Jun 20 [cited 2018 Dec 17];307(23):2526-33. Available from: http://jama.jamanetwork.com/article.aspx?doi=10.1001/jama.2012.5669

4. Papazian L, Forel J-M, Gacouin A, Penot-Ragon C, Perrin G, Loundou A, et al. Neuromuscular Blockers in Early Acute Respiratory Distress Syndrome. N Engl J Med [Internet]. 2010 Sep 16 [cited 2018 Dec 17];363(12):1107-16. Available from: http://www.nejm.org/doi/abs/10.1056/NEJMoa1005372

5. Combes A, Hajage D, Capellier G, Demoule A, Lavoué S, Guervilly C, et al. Extracorporeal Membrane Oxygenation for Severe Acute Respiratory Distress Syndrome. N Engl J Med [Internet]. 2018 May 24 [cited 2018 Dec 17];378(21):1965-75. Available from: http://www.nejm.org/doi/10.1056/NEJMoa1800385

6. Ferguson ND, Cook DJ, Guyatt GH, Mehta S, Hand L, Austin P, et al. High-Frequency Oscillation in Early Acute Respiratory Distress Syndrome. N Engl J Med [Internet]. 2013 Feb 28 [cited 2019 Apr 5];368(9):795-805. Available from: http://www.nejm.org/doi/10.1056/NEJMoa1215554

7. Young D, Lamb SE, Shah S, MacKenzie I, Tunnicliffe W, Lall R, et al. High-Frequency Oscillation for Acute Respiratory Distress Syndrome. N Engl J Med [Internet]. 2013 Feb 28 [cited 2019 Apr 5];368(9):806-13. Available from: http://www.nejm.org/doi/10.1056/NEJMoa1215716

8. Peek GJ, Mugford M, Tiruvoipati R, Wilson A, Allen E, Thalanany MM, et al. Efficacy and economic assessment of conventional ventilatory support versus extracorporeal membrane oxygenation for severe adult respiratory failure (CESAR): a multicentre randomised controlled trial. Lancet [Internet]. 2009 Oct 17 [cited 2018 Dec 17];374(9698):1351-63. Available from: https://www-sciencedirect-com.ccmain.ohionet.org/science/article/pii/S0140673609610692?via\%3Dihub

9. Guérin C, Reignier J, Richard J-C, Beuret P, Gacouin A, Boulain T, et al. Prone Positioning in Severe Acute Respiratory Distress Syndrome. N Engl J Med [Internet]. 2013 Jun 6 [cited 2018 Dec 17];368(23):2159-68. Available from: http://www.nejm.org/doi/10.1056/NEJMoa1214103

10. Network TARDS. Ventilation with Lower Tidal Volumes as Compared with Traditional Tidal Volumes for Acute Lung Injury and the Acute Respiratory Distress Syndrome. N Engl J Med [Internet]. 2000 May 4 [cited 2018 Dec 17];342(18):1301-8. Available from: http://www.nejm.org/doi/abs/10.1056/NEJM200005043421801

11. Moss M, Huang DT, Brower RG, Ferguson ND, Ginde AA, Gong MN, et al. Early Neuromuscular Blockade in the Acute Respiratory Distress Syndrome. N Engl J Med [Internet]. 2019 May 23 [cited 2020 Mar 23];380(21):1997-2008. Available from: http://www.nejm.org/doi/10.1056/NEJMoa1901686 
12. Villar J, Kacmarek RM, Pérez-Méndez L, Aguirre-Jaime A. A high positive end-expiratory pressure, low tidal volume ventilatory strategy improves outcome in persistent acute respiratory distress syndrome: A randomized, controlled trial*. Crit Care Med [Internet]. 2006 May [cited 2018 Dec 17];34(5):1311-8. Available from: https://insights.ovid.com/crossref? an=00003246-200605000-00002

13. Amato MBP, Barbas CSV, Medeiros DM, Magaldi RB, Schettino GP, Lorenzi-Filho G, et al. Effect of a Protective-Ventilation Strategy on Mortality in the Acute Respiratory Distress Syndrome. N Engl J Med [Internet]. 1998 Feb 5 [cited 2018 Dec 17];338(6):347-54. Available from: http://www.nejm.org/doi/abs/10.1056/NEJM199802053380602

14. Taylor RW, Zimmerman JL, Dellinger RP, Straube RC, Criner GJ, Kenneth Davis J, et al. Low-Dose Inhaled Nitric Oxide in Patients With Acute Lung Injury\&It;SUBTITLE\&gt;A Randomized Controlled Trial\&It;/SUBTITLE\&gt; JAMA [Internet]. 2004 Apr 7 [cited 2018 Dec 17];291(13):1603. Available from: http://jama.jamanetwork.com/article.aspx? doi $=10.1001 /$ jama 291.13 .1603

15. Adhikari NKJ, Dellinger RP, Lundin S, Payen D, Vallet B, Gerlach H, et al. Inhaled Nitric Oxide Does Not Reduce Mortality in Patients With Acute Respiratory Distress Syndrome Regardless of Severity. Crit Care Med [Internet]. 2014 Feb [cited 2018 Dec 17];42(2):404-12. Available from: https://insights.ovid.com/crossref?an=00003246-201402000-00021

16. The National Heart L and BIARDS (ARDS) CTN. Comparison of Two Fluid-Management Strategies in Acute Lung Injury. N Engl J Med [Internet]. 2006 Jun 15 [cited 2018 Dec 17];354(24):2564-75. Available from:

http://www.nejm.org/doi/abs/10.1056/NEJMoa062200

17. Noah MA, Peek GJ, Finney SJ, Griffiths MJ, Harrison DA, Grieve R, et al. Referral to an Extracorporeal Membrane Oxygenation Center and Mortality Among Patients With Severe 2009 Influenza A(H1N1). JAMA [Internet]. 2011 Oct 19 [cited 2018 Dec 17];306(15):1659. Available from: http://jama.jamanetwork.com/article.aspx? doi $=10.1001 /$ jama. 2011.1471

18. Pham T, Combes A, Rozé H, Chevret S, Mercat A, Roch A, et al. Extracorporeal Membrane Oxygenation for Pandemic Influenza A(H1N1)-induced Acute Respiratory Distress Syndrome. Am J Respir Crit Care Med [Internet]. 2013 Feb 5 [cited 2018 Dec 17];187(3):276-85. Available from: http://www.atsjournals.org/doi/abs/10.1164/rccm.201205-08150C

19. Amato MBP, Meade MO, Slutsky AS, Brochard L, Costa ELV, Schoenfeld DA, et al. Driving Pressure and Survival in the Acute Respiratory Distress Syndrome. N Engl J Med [Internet]. 2015 Feb 19 [cited 2019 Mar 16];372(8):747-55. Available from: http://www.nejm.org/doi/10.1056/NEJMsa1410639

20. Sterne JAC, Savović J, Page MJ, Elbers RG, Blencowe NS, Boutron I, et al. RoB 2: A revised tool for assessing risk of bias in randomised trials. BMJ. 2019;366.

21. Sterne JA, Hernán MA, Reeves BC, Savović J, Berkman ND, Viswanathan M, et al. ROBINS-I: A tool for assessing risk of bias in non-randomised studies of interventions. BMJ. 2016;355.

22. Nyaga VN, Arbyn M, Aerts M. Metaprop: a Stata command to perform meta-analysis of binomial data. Arch Public Health [Internet]. 2014 [cited 2018 Dec 17];72(1):39. Available from: http://www.ncbi.nlm.nih.gov/pubmed/25810908

23. Higgins JPT, Thompson SG, Deeks JJ, Altman DG. Measuring inconsistency in meta-analyses. BMJ [Internet]. 2003 Sep 6 [cited 2019 Jan 29];327(7414):557-60. Available from: http://www.ncbi.nlm.nih.gov/pubmed/12958120

24. Baker WL, Michael White C, Cappelleri JC, Kluger J, Coleman Cl, Health Outcomes, Policy, and Economics (HOPE) Collaborative Group. Understanding heterogeneity in meta-analysis: the role of meta-regression. Int J Clin Pract [Internet]. 2009 Oct [cited 2019 Jan 29];63(10):1426-34. Available from: http://www.ncbi.nlm.nih.gov/pubmed/19769699

25. Liu Z, Yao Z, Li C, Liu X, Chen H, Gao C. A step-by-step guide to the systematic review and meta-analysis of diagnostic and prognostic test accuracy evaluations. Br J Cancer [Internet]. 2013 Jun 11 [cited 2019 Mar 19];108(11):2299-303. Available from: http://www.ncbi.nlm.nih.gov/pubmed/23695015

26. Egger M, Davey Smith G, Schneider M, Minder C. Bias in meta-analysis detected by a simple, graphical test. BMJ [Internet]. 1997 Sep 13 [cited 2019 Aug 31];315(7109):629-34. Available from: http://www.ncbi.nlm.nih.gov/pubmed/9310563

27. C Sterne professor JA, Sutton professor AJ. Recommendations for examining and interpreting funnel plot asymmetry in meta-analyses of randomised controlled trials. [cited 2019 Aug 31]; Available from:

http://www.bmj.com/content/342/bmj.d4002/suppl/DC1

Page 9/16 
28. Guervilly C, Lacroix R, Forel JM, Roch A, Camoin-Jau L, Papazian L, et al. High levels of circulating leukocyte microparticles are associated with better outcome in acute respiratory distress syndrome. Crit Care [Internet]. 2011 Jan 18 [cited 2020 Jul 17];15(1):R31. Available from: /pmc/articles/PMC3222067/?report=abstract

29. Needham DM, Yang T, Dinglas VD, Mendez-Tellez PA, Shanholtz C, Sevransky JE, et al. Timing of Low Tidal Volume Ventilation and Intensive Care Unit Mortality in Acute Respiratory Distress Syndrome. A Prospective Cohort Study. Am J Respir Crit Care Med [Internet]. 2015 Jan 15 [cited 2019 Aug 24];191(2):177-85. Available from: http://www.atsjournals.org/doi/abs/10.1164/rccm.201409-15980C

30. Needham DM, Colantuoni E, Mendez-Tellez PA, Dinglas VD, Sevransky JE, Dennison Himmelfarb CR, et al. Lung protective mechanical ventilation and two year survival in patients with acute lung injury: prospective cohort study. BMJ [Internet]. 2012 Apr 5 [cited 2019 Aug 24];344:e2124. Available from: http://www.ncbi.nlm.nih.gov/pubmed/22491953

31. Constantin JM, Jabaudon M, Lefrant JY, Jaber S, Quenot JP, Langeron O, et al. Personalised mechanical ventilation tailored to lung morphology versus low positive end-expiratory pressure for patients with acute respiratory distress syndrome in France (the LIVE study): a multicentre, single-blind, randomised controlled trial. Lancet Respir Med [Internet]. 2019 Oct 1 [cited 2020 Jul 17];7(10):870-80. Available from: http://dx.doi.org/10.1016/

32. Levy MM. PEEP in ARDS - How Much Is Enough? N Engl J Med [Internet]. 2004 Jul 22 [cited 2019 Aug 31];351(4):389-91. Available from: http://www.ncbi.nlm.nih.gov/pubmed/15269320

33. Kahan BC, Rehal S, Cro S. Risk of selection bias in randomised trials. Trials [Internet]. 2015 [cited 2019 Apr 5];16. Available from: https://www.ncbi.nlm.nih.gov/pmc/articles/PMC4566301/

34. Hannan EL. Randomized Clinical Trials and Observational Studies: Guidelines for Assessing Respective Strengths and Limitations. JACC Cardiovasc Interv [Internet]. 2008 Jun 1 [cited 2019 Aug 24];1(3):211-7. Available from:

https://www.sciencedirect.com/science/article/pii/S1936879808001702?via\%3Dihub

35. Zhang Z, Spieth PM, Chiumello D, Goyal H, Torres ; Antoni, Laffey JG, et al. Declining Mortality in Patients With Acute Respiratory Distress Syndrome. Crit Care Med [Internet]. 2019 Mar [cited 2019 Mar 16];47(3):315-23. Available from: http://insights.ovid.com/crossref?an=00003246-201903000-00002

36. Esteban A, Alía I, Gordo F, Raú L De Pablo ;, Suarez J, Gonzá Lez G, et al. Prospective Randomized Trial Comparing Pressure-Controlled Ventilation and Volume-Controlled Ventilation in ARDS* [Internet]. Vol. 117, CHEST. 2000 [cited 2019 Aug 24]. Available from: https://journals-ohiolink-edu.ccmain.ohionet.org/pg_99? 308415134769066::NO::P99_ENTITY_ID,P99_ENTITY_TYPE:269705777,MAIN_FILE\&cs=3CPgTWHiT1jDXKOIOMXnjvYhkBVqUOm3yV4ELb-5KbMDluDqWYOLOmnqKDFihePg_33jdmqml8NrrWK-qjHtLw

37. Fialkow L, Rios SR, Andréia V, Fernandes K, Rossato D, Mary S, et al. B R I E F R E P O RT Acute lung injury and acute respiratory distress syndrome at the intensive care unit of a general university hospital in Brazil. Intensive Care Med [Internet]. 2002 [cited 2019 Aug 24];28:1644-8. Available from: https://link-springer-

com.ccmain.ohionet.org/content/pdf/10.1007/s00134-002-1507-z.pdf

38. Fan E, Del Sorbo L, Goligher EC, Hodgson CL, Munshi L, Walkey AJ, et al. An Official American Thoracic Society/European Society of Intensive Care Medicine/Society of Critical Care Medicine Clinical Practice Guideline: Mechanical Ventilation in Adult Patients with Acute Respiratory Distress Syndrome. Am J Respir Crit Care Med [Internet]. 2017 May 1 [cited 2019 Aug 24];195(9):1253-63. Available from: http://www.atsjournals.org/doi/10.1164/rccm.201703-0548ST

\section{Tables}

\section{Table 1: Study Characteristics}




\begin{tabular}{|c|c|c|c|c|}
\hline Characteristics & All (\% reporting) & RCT (\% reporting) & Observational (\% reporting) & $p$ value \\
\hline \multicolumn{5}{|l|}{ ARDS Criteria^ } \\
\hline Berlin & $36(42.4 \%)$ & $8(9.5 \%)$ & $28(33.3 \%)$ & \\
\hline AECC & $46(54.0 \%)$ & $21(24.7 \%)$ & $25(30.0 \%)$ & \\
\hline Berlin or AECC & $2(2.4 \%)$ & 0 & $2(2.4 \%)$ & \\
\hline Other & $1(1.2 \%)$ & $1(1.6 \%)$ & 0 & \\
\hline Mortality & $38 \%$ & $35 \%$ & $40 \%$ & $0.04^{a}$ \\
\hline Age, years* & $55.9 \pm 7.4(82.4 \%)$ & $56.2 \pm 4.5(34.1 \%)$ & $55.7 \pm 9.1(48.2 \%)$ & $0.84^{\mathrm{a}}$ \\
\hline $\mathrm{PaO}_{2} / \mathrm{FiO}_{2}, \mathrm{~mm} \mathrm{Hg}^{*}$ & $131.7 \pm 31.0(84.7 \%)$ & $133 \pm 28.3(34.1 \%)$ & $130.8 \pm 33.0(50.6 \%)$ & $0.77^{\mathrm{a}}$ \\
\hline APACHE II* & $22.1 \pm 3.4(44.7 \%)$ & $21.0 \pm 3.0(16.5 \%)$ & $22.8 \pm 3.5(28.2 \%)$ & $0.10^{\mathrm{a}}$ \\
\hline SOFA* & $9.4 \pm 1.8(37.6 \%)$ & $9.2 \pm 1.8(14.1 \%)$ & $9.6 \pm 1.8(23.5 \%)$ & $0.58^{a}$ \\
\hline Tidal Volume, $\mathrm{ml} / \mathrm{kg}^{\star}$ & $7.19 \pm 0.85(65.8 \%)$ & $7.10 \pm 0.90(32.9 \%)$ & $7.29 \pm 0.81(32.9 \%)$ & $0.39^{a}$ \\
\hline PEEP, $\mathrm{cm} \mathrm{H} \mathrm{H}_{2} \mathrm{O}^{*}$ & $10.2 \pm 2.0(71.8 \%)$ & $10.9 \pm 2.2(30.6 \%)$ & $9.7 \pm 1.6(41.2 \%)$ & $0.02^{\mathrm{a}}$ \\
\hline Plateau Pressure, $\mathrm{cm} \mathrm{H}_{2} 0^{*}$ & $25.7 \pm 2.8(58.8 \%)$ & $26.0 \pm 2.6(29.4 \%)$ & $25.4 \pm 3.0(29.4 \%)$ & $0.46^{\mathrm{a}}$ \\
\hline Driving Pressure, $\mathrm{cm} \mathrm{H}_{2} \mathrm{O}^{*}$ & $15.4 \pm 2.2(52.9 \%)$ & $15.4 \pm 2.1(27.1 \%)$ & $15.5 \pm 2.2(25.8 \%)$ & $0.77^{\mathrm{a}}$ \\
\hline Inhaled Vasodilators^ & $23(27.1 \%)$ & $7(8.2 \%)$ & $16(18.9 \%)$ & $0.18^{a}$ \\
\hline $\mathrm{NMBA}^{\wedge}$ & $22(26 \%)$ & $10(11.8 \%)$ & $12(14.2 \%)$ & $0.50^{\mathrm{a}}$ \\
\hline $\mathrm{HFOV}^{\wedge}$ & $9(10.6 \%)$ & $4(4.7 \%)$ & $5(5.9 \%)$ & $0.40^{a}$ \\
\hline Prone Positioning^ & $25(29.4 \%)$ & $9(10.6 \%)$ & $16(18.8 \%)$ & $0.48^{\mathrm{a}}$ \\
\hline $\mathrm{ECMO}^{\wedge}$ & $20(23.5 \%)$ & $5(5.9 \%)$ & $15(17.6 \%)$ & $0.07^{a}$ \\
\hline \multicolumn{5}{|l|}{ Continent ${ }^{\wedge}$} \\
\hline Europe & $34(40.0 \%)$ & $14(16.4 \%)$ & $20(23.5 \%)$ & \\
\hline North America & 19 (22.3\%) & $6(7.1 \%)$ & $13(15.3 \%)$ & \\
\hline Asia & $25(29.4 \%)$ & $6(7.1 \%)$ & 19 (22.3\%) & \\
\hline Australia & $1(1.2 \%)$ & 0 & $1(1.2 \%)$ & \\
\hline South America & $\begin{array}{l}1(1.2 \%) \\
5(5.9 \%)\end{array}$ & 0 & $1(1.2 \%)$ & \\
\hline Global & & $4(4.7 \%)$ & $1(1.2 \%)$ & \\
\hline
\end{tabular}

Table 1 - ^Number of studies (\%); *Mean \pm SD (\% studies reporting); ${ }^{\text {a }}$ by t-test; RCT: randomized controlled trial; AECC: American European Consensus Conference; APACHE II: Acute; Physiology and Chronic Health Evaluation; SOFA: Sequential Organ Failure Assessment; PEEP: positive end-expiratory pressure; NMBA: neuromuscular blocking agent; HFOV: high frequency oscillatory ventilation; ECMO: extracorporeal membrane oxygenation. Statistically significant variables are bolded. 


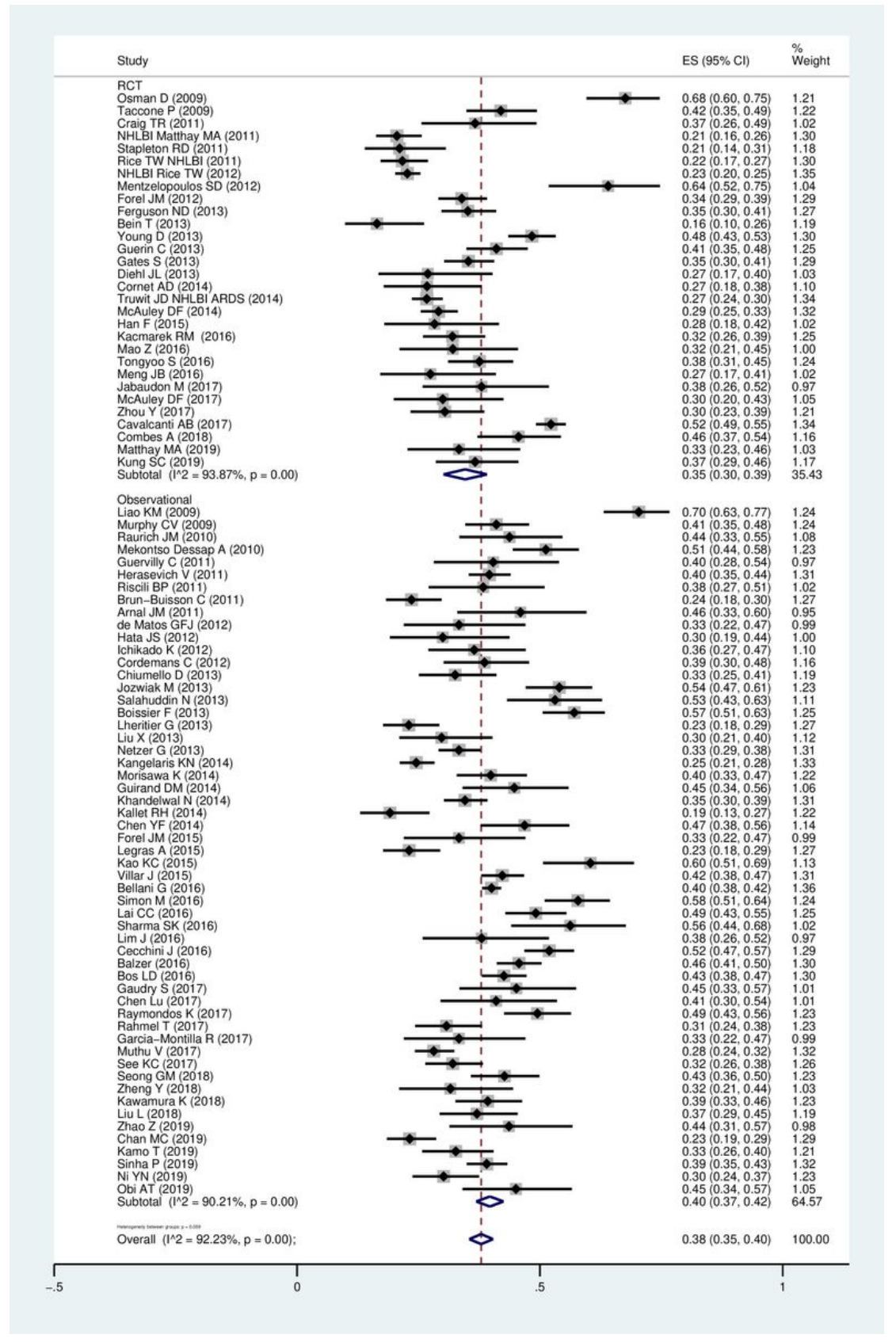

\section{Figure 1}

Study selection process Legend - Study selection process. More than one reason possible for study for study exclusion. Details on included studies available further in supplementary data. 


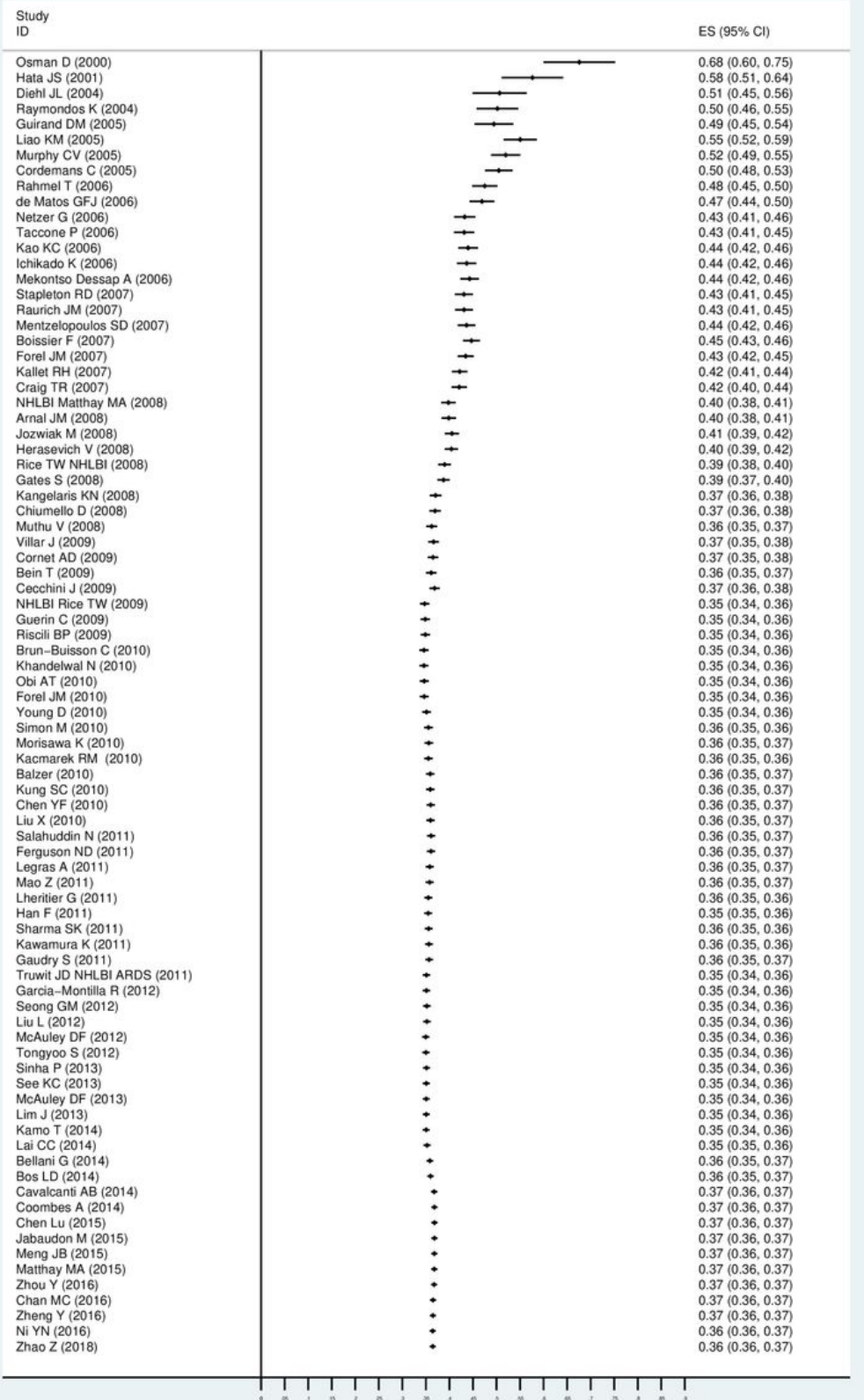

\section{Figure 2}

Forest plot of mortality for all studies included Legend - Forest plot of mortality for all studies included organized by RCT vs Observational study design. Listed in chronological order by year of publication (in parenthesis). $95 \% \mathrm{Cl}$ listed with point estimate of each individual study (vertical lines) and pooled estimate in observational studies, RCT, and in totality (vertical line and diamond). 


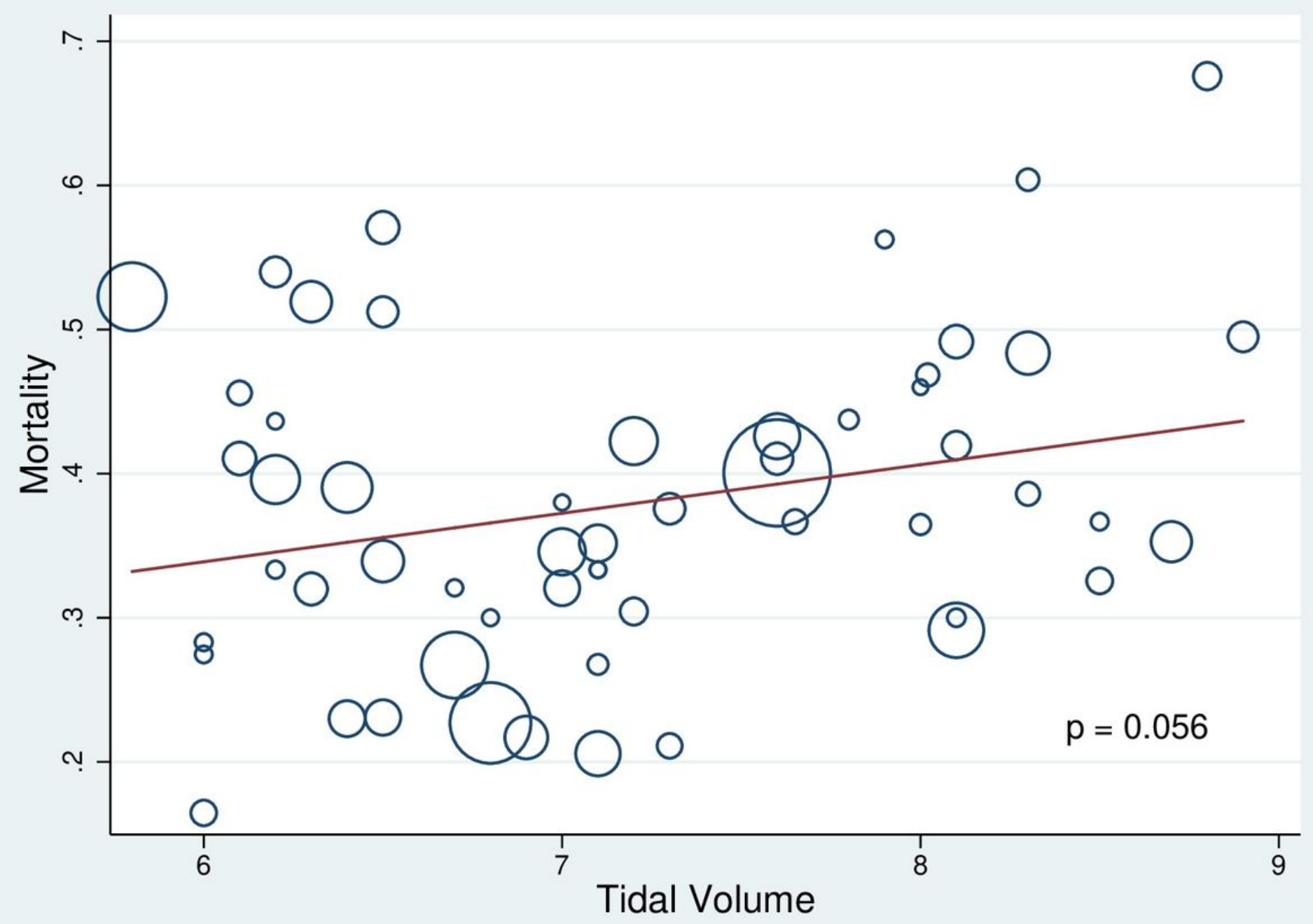

Figure 3

Cumulative mortality analysis Legend - Cumulative mortality analysis from 2000 - 2018 including each individual study. Listed in chronological order by median year of enrollment (in parenthesis). 


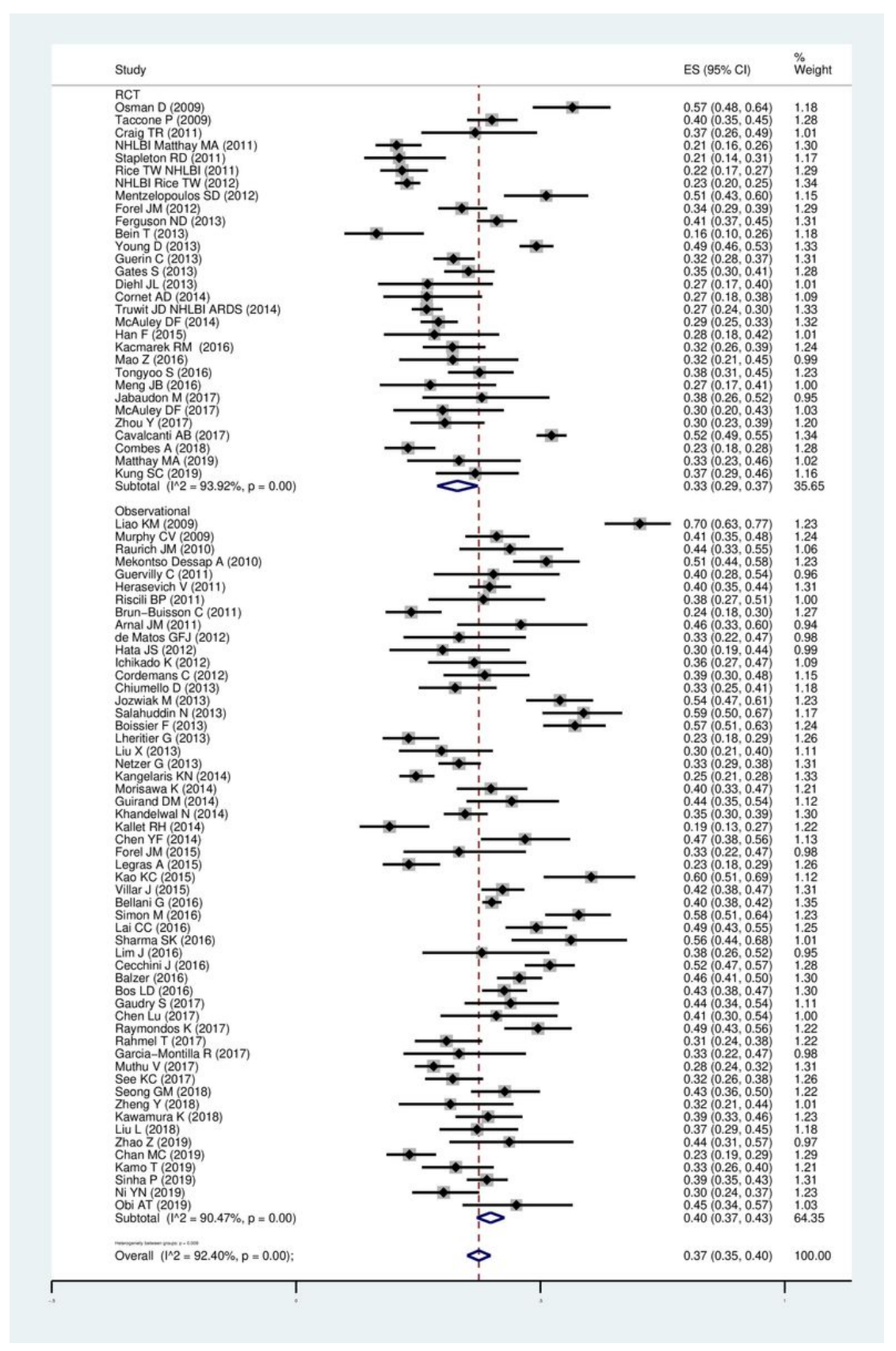

\section{Figure 4}

Meta-regression analysis of $\mathrm{PaO} 2 / \mathrm{FiO} 2$ Legend - Meta-regression analysis of $\mathrm{PaO} 2 / \mathrm{FiO} 2(\mathrm{mmHg})$. Mortality listed on y axis and $\mathrm{PaO} 2 / \mathrm{FiO} 2$ on $x$ axis. Circles represent each individual study and vertical line represents meta-regression line. The $\mathrm{p}$ value is reported on bottom right. 


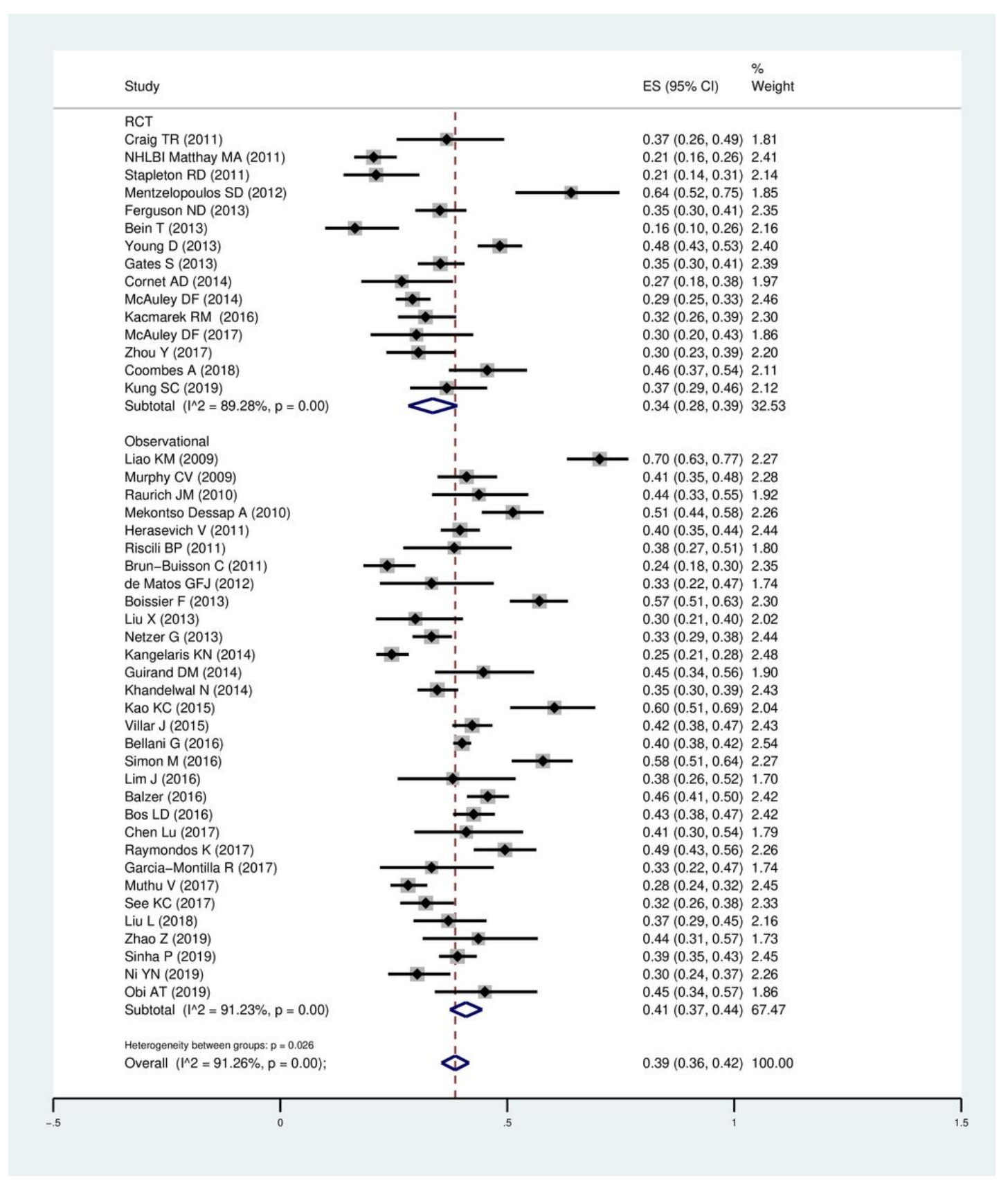

\section{Figure 5}

Meta-regression analysis of Tidal Volume Legend - Meta-regression analysis of Tidal Volume $(\mathrm{ml} / \mathrm{kg})$. Mortality listed on y axis and Tidal Volume on $x$ axis. Circles represent each individual study and vertical line represents meta-regression line. The $p$ value is reported on bottom right.

\section{Supplementary Files}

This is a list of supplementary files associated with this preprint. Click to download.

- SupplementaryAppendixUpdated.docx 